\title{
SERVIÇOS ARQUIVÍSTICOS TERCEIRIZADOS NA PETROBRAS
}

\author{
ARCHIVAL SERVICES OUTSOURCED AT PETROBRAS
}

\author{
José Antonio Pereira do Nascimento ${ }^{1}$, Ana Celeste Indolfo \\ ${ }_{1}^{1}$ Petrobras, Gerência Setorial de Documentação Técnica e Legal Ativos de Produção, Brasil, e-mail: \\ zetorio@petrobras.com.br \\ 2 Universidade Federal do Estado do Rio de Janeiro, Programa de Pós-Graduação em Gestão de \\ Documentos e Arquivos, Brasil, e-mail: indolfo@gmail.com
}

\begin{abstract}
ARTICLE INFO
Article history:

Received 2018-08-15

Accepted 2019-02-06

Available online 2019-02-07

Palavras-chave: Serviços arquivísticos. Terceirização.

Petrobras.

Keywords: Archival services; Outsourcing. Petrobras

RESUMO. O trabalho apresenta o histórico da terceirização no Brasil e sua evolução jurídica a partir do final da década 1960. Por meio de revisão de literatura, traz o significado e evolução do conceito de terceirização, explicitando o que sejam serviços terceirizados. Identifica na legislação brasileira quais as regras estabelecidas quanto à terceirização de serviços, de forma geral e, especificamente, quanto à terceirização de serviços arquivísticos. Explicita que na falta de uma norma legal que regulamentasse a terceirização, a jurisprudência trabalhista, por meio da Súmula no 331 do Tribunal Superior do Trabalho (TST), resumiu a legislação esparsa existente no Brasil, sendo esta Súmula, até a data de 31 de março de 2017, a principal normatização sobre serviços terceirizados no Brasil, quando, então, foi sancionada a Lei no 13.429 que regulamentou a matéria. Descreve a aplicação de instrumento de coleta de dados, enviado a quatro gerentes de serviços de gestão de documentos de uma empresa estatal brasileira do ramo de energia, a Petrobras, e, uma vez realizada a análise dos dados, apresentam-se resultados de comparação entre recursos humanos próprios e terceirizados alocados por meio de contratos de serviços arquivísticos celebrados com a estatal.
\end{abstract}

\begin{abstract}
The paper presents the history of outsourcing in Brazil and its legal evolution from the end of the 1960s. Through a literature review brings the meaning and evolution of the concept of outsourcing, explaining what outsourced services. It identifies in Brazilian legislation the rules established regarding the outsourcing of services, in general, and specifically, regarding the outsourcing of archival services. It clarifies that, in the absence of a legal rule that regulates outsourcing, labor jurisprudence, through Legal Summary 331 of Brazilian Supreme Court of Labor (TST), summarized the existing sparse legislation in Brazil, this Summary being, until the date of March 31, 2017, the main standardization on outsourced services in Brazil, when, at that time, Law No. 13,429, which regulated the matter, was sanctioned. Describes the application of data collection instrument sent to four managers of records management services of a Brazilian state-owned company, the Petrobras, once the data analysis is performed, the results are compared between own and outsourced human resources through service contracts.
\end{abstract}




\section{Introdução}

Apresenta-se o tema da terceirização de serviços de forma geral, explicitando seu conceito e indicando a legislação brasileira a respeito, expondo o histórico da terceirização no Brasil e sua evolução jurídica a partir do final da década 1960 de forma sucinta.

Este trabalho identifica na legislação brasileira quais as regras estabelecidas quanto à terceirização de serviços, de forma geral e, especificamente, quanto à terceirização de serviços arquivísticos. Por meio de revisão de literatura, traz o conceito e evolução do conceito de terceirização, explicitando o que sejam serviços terceirizados.

Verificar-se-á que na falta de uma norma legal que regulamentasse a terceirização, a jurisprudência trabalhista, por meio da Súmula oㅜ 331 do Tribunal Superior do Trabalho (TST), resumiu a legislação esparsa existente no Brasil, sendo esta Súmula, até a data de 31 de março de 2017, a principal normatização sobre serviços terceirizados no Brasil, quando, então, foi sancionada a Lei $\mathrm{n}^{0} 13.429$ que regulamentou a matéria.

Este trabalho traz, ainda, o resultado de uma pesquisa empírica sobre recursos humanos de contratos de serviços arquivísticos terceirizados, realizada em uma empresa estatal brasileira do ramo de energia, a Petrobras. Após aplicação de instrumento de coleta de dados, enviado a quatro gerentes de serviços de gestão de documentos, que após a análise dos dados realizada faz uma comparação entre recursos humanos próprios e terceirizados por meio de contratos de serviços arquivísticos celebrados.

Por fim, apresentam-se as considerações finais em relação à legislação de serviços arquivísticos terceirizados e sobre o cenário no momento atual.

\section{Serviços terceirizados}

O termo "serviços terceirizados" foi verificado preliminarmente em três dicionários técnicos de Arquivologia brasileiros: "Dicionário Brasileiro de Terminologia Arquivística", "Dicionário de Biblioteconomia e Arquivologia" e "Dicionário de terminologia arquivística". Não foi encontrado o termo em nenhum deles, bem como, não foi encontrada uma definição no "Vocabulário Jurídico" de De Plácido e Silva.

Talvez esta ausência nos dicionários citados se dê pelo que afirma Porto (2014, p. 157), que a "terceirização não é um instituto jurídico, sendo na realidade um fenômeno pertencente a outras áreas do conhecimento, especialmente à economia e à administração de empresas". Concorda-se com Porto e, por isso, neste trabalho, se afirma que a terceirização da qual se trata é aquela na visão administrativa empresarial e não a do Direito Trabalhista. Reforça-se, 
portanto a complexidade do tema, pois, ainda, se poderia adentrar na esfera social ou política do tema.

A terceirização não é um tema próprio da Arquivologia, todavia, seus impactos jurídicos, sociais ou empresariais podem afetar os profissionais da área e, quiçá, na qualidade da aplicação de conceitos teóricos da área nos arquivos empresariais. Ocorrendo isso, a terceirização se torna sim um tema de discussão de arquivistas e demais profissionais da informação no que tange à sua educação e trabalho.

Durante a maior parte do tempo dedicado a pesquisa de mestrado profissional em gestão de documentos e arquivos, do qual este trabalho é um dos frutos, não havia no Brasil um marco legal abrangente sobre terceirização de serviços. Quase todas as interpretações e resoluções de litígios se realizavam à baila da Súmula 331 do Tribunal Superior do Trabalho (TST).

Em 31 de março de 2017, contudo, foi sancionada a Lei no 13.429, que mudou completamente o cenário jurídico, sem que, até o final deste trabalho, se pudessem verificar teoricamente ou empiricamente seus efeitos no Direito Trabalhista, bem como no desempenho das empresas ou nos serviços arquivísticos terceirizados.

A Lei ainda está sendo questionada por várias entidades. No dia 3 de abril de 2017, por exemplo, o partido Rede sustentabilidade protocolou Ação Direta de Inconstitucionalidade (ADI) no Supremo Tribunal Federal, que foi distribuído ao Ministro Gilmar Mendes, sob o n 5.685 . No dia 5 de abril de 2017, foi a vez da Confederação Nacional dos Profissionais Liberais e do Partido Comunista do Brasil protocolarem ações da mesma espécie (ADI nํ⒌686 e nํㅜ․687 respectivamente) ${ }^{1}$.

Em 10 de abril de 2017, o Ministro Gilmar Mendes, Inicialmente, por verificar que se tratavam do mesmo tema, determinou o apensamento das ADI n 5.686 e $n \cong 5.687$ à Ação Direta de Inconstitucionalidade $\mathrm{n}^{0}$ 5.685, para que tenham tramitação simultânea e sejam julgadas conjuntamente. Em 17 de abril de 2017 a Confederação Nacional dos Trabalhadores na Indústria Química e da Confederação Nacional dos Trabalhadores nas Indústrias Têxtil, Vestuário, Couro e Calçados protocolaram juntas a ADI nํ 5.695. Em 27 de junho de 2017 o Procurador-Geral da República também protocolou a ADI ํㅜ 5.735. Estas duas também foram apensadas à primeira ADI no 5.685. Até a finalização deste trabalho, as ações aguardavam julgamento.

Especificamente, sobre serviços arquivísticos terceirizados há normatização para a Administração Pública por meio da Resolução ํㅜ 6, de 15 de maio de 1997, do CONARQ.

\footnotetext{
${ }^{1}$ Supremo Tribunal Federal. Disponível em: http://www.stf.jus.br/portal/processo/verProcessoAndamento.asp?incidente=5165589. Acesso em: 11 jun. 2017.
} 
Di Pietro (2012, p. 215) afirma que na Administração Pública "pode-se dizer que a terceirização constitui uma das formas de privatização".

O aumento da terceirização no Brasil está ligado ao momento do desenvolvimento do capitalismo global, ciclicamente em crise. Principalmente após crise do fordismo-keynesianismo na União Europeia, incapaz ampliar direitos trabalhistas. A partir de 1990, difundiu-se no mercado de trabalho formas de contratação objetivando redução de custos, chegando tal tendência também ao frágil mercado do Brasil. Mantendo ainda a tendência de precarização do trabalho, articulando, por um lado, acumulação flexível e, por outro lado, acumulação por espoliação. Se os novos elementos conseguem dar dinamismo à acumulação e superar a crise do fordismo e articular a configuração de um novo regime para esta acumulação e forma de regulação é uma questão para os regulacionistas (ARIENTI, 2002, p. 7-9; TEIXEIRA; PELATIERI, 2009, p. 19-21; ALVES, 2014, p. 102-104):

Com o neoliberalismo, a lógica autoexpansionista [sic] do capital imprimiu sua marca nas instituições jurídico-políticas da ordem burguesa, tornando-as insensíveis aos argumentos humanísticos e valores sociais. Os Sumos Sacerdotes do mercado clamam pelo princípio da iniciativa privada. Predomina no discurso das personificações do capital o pragmatismo de ocasião, que reitera, como um destino irremediável, a adaptação à nova ordem global. A palavra de ordem é flexibilizar as relações de trabalho (ARIENTI, 2002, p. 102).

A taxa de salário não é apenas o custo do trabalho, também é determinante do nível de demanda agregada e, portanto, da demanda por mão-de-obra. Enquanto um aumento salarial desencorajará o emprego aumentando o custo desse insumo, também poderá promover o emprego, apoiando um maior nível de demanda (BOWLES; BOYER, p. 144).

A terceirização realizada por empresas privadas, segundo Di Pietro (2012, p. 216), é a contratação de serviços de terceiro para o desempenho de atividades-meio. Essa contratação pode assumir diversas formas como empreitada de obra ou de serviço, franquia, fornecimento de mão de obra etc.

Porto (2014, p. 150-151), que faz uma linha do tempo dos meios de produção utilizados pela sociedade ao longo da história até chegar à "estratégia empresarial" da terceirização, conceitua esta como "o processo de repasse para a realização de complexo de atividades por empresa especializada, sendo que estas atividades poderiam ser desenvolvidas pela própria empresa" (CARELLI, 2003, p. 77-78 apud PORTO, 2014, p. 157).

Para Balbino e Silva (2016, p. 102), o termo outsourcing, de origem inglesa, começou a ser utilizado no Brasil na década de 1980, mas segundo estes mesmos autores, o termo "terceirização" foi criado no Brasil, na década de 1970. Balbino e Silva utilizam os dois vocábulos como sinônimos que significam: 
[...] buscar obter mão de obra externa à empresa, ou seja, mão de obra terceirizada. O outsourcing é uma forma de tornar um centro de custos interno em um serviço externo, por meio da subcontratação, liberando recurso da organização e gestores para convergirem a sua atenção nas áreas de negócio de importância estratégica (BALBINO; SILVA, 2016, p. 102-103).

O termo "terceirização" é o que se utiliza neste trabalho, pois se acredita que, uma vez que há na língua vernácula um vocábulo para designar um determinado conceito, prescinde-se de utilização de estrangeirismos.

Carvalho e Corrêa (2014, p. 36), ainda, classificam a terceirização como podendo ser parcial ou integral.

\begin{abstract}
A terceirização pode apresentar-se como parcial ou integral. Se parcial, os gestores da empresa tomadora dos serviços exercem o poder diretivo sobre os empregados da empresa interposta, a exemplo do que sucede no trabalho temporário regido pela Lei oㅡ 6.019/742. Sendo integral, o trabalho terceirizado é comandado e remunerado pelos gestores da empresa interposta, assim se verificando na terceirização de atividade-meio que se coaduna verdadeiramente com a conveniência de terceirizar serviços especializados, conforme consentido pela Súmula oo 331 do TST. A terceirização parcial tem lugar no ambiente da empresa tomadora dos serviços, enquanto a terceirização integral ocorre nesse mesmo ambiente ou naquele provido pela empresa interposta (CARVALHO; CORRÊA, 2014, p. 36).
\end{abstract}

Tanto para Porto (2014, p. 154), quanto para Carvalho e Corrêa (2014, p. 37), o início na previsão legal da terceirização no Brasil ocorre com o Decreto Lei no 200, de 25 de fevereiro de 1967, que dispõe sobre a organização da Administração Pública Federal.

Para Porto (2014, p. 156-157), na falta de uma norma legal que regulamente a terceirização, a jurisprudência trabalhista, por meio da Súmula oㅡ 331 do TST, resumiu a legislação esparsa existente no Brasil.

A Súmula no 331 do TST, era, portanto, até então, quando foi sancionada a Lei ํo 13.429, de 31 de março de 2017, a principal "normatização" sobre serviços terceirizados no Brasil.

A nova Lei redefiniu, inclusive, o trabalho temporário, que deixou de ser aquele prestado por pessoa física a uma empresa, para atender à necessidade transitória de substituição de seu pessoal regular e permanente ou a acréscimo extraordinário de serviços, para ser:

aquele prestado por pessoa física contratada por uma empresa de trabalho temporário que a coloca à disposição de uma empresa tomadora de serviços, para atender à necessidade de substituição transitória de pessoal permanente ou à demanda complementar de serviços (BRASIL, 2017).

A nova descrição traz os conceitos e "empresa de trabalho temporário", "empresa tomadora de serviços", regulamentando, assim, as empresas específicas de serviços

2 Lei alterada pela Lei no 13.429 , de 31 de março de 2017. 
temporários. Estas empresas e não somente o trabalhador individual, poderão realizar serviços "temporários" que não serão mais o extraordinário, mas também aquele considerado complementar.

Para Führer, M. C. e Führer, M. R. (2005, p. 52) o resumo da terceirização no Brasil estava dividido em duas regras básicas:

PRIMEIRA - A contratação de trabalhadores por empresa interposta é ilegal, formando-se o vínculo diretamente com o tomador dos serviços, salvo quatro exceções:

- trabalho temporário

- contratação com a Administração Pública

- contratação de serviços de vigilância, de conservação, de limpeza

- contratação de serviços especializados ligados à atividade-meio do tomador, desde que inexistam pessoalidade e subordinação direta.

SEGUNDA - No caso de inadimplemento das obrigações trabalhistas por parte do empregador sempre haverá responsabilidade subsidiária do tomador, desde que ele tenha participado do processo judicial de conhecimento e conste do título executivo. (FÜHRER, M. C.; FÜHRER, M. R., 2005, p. 52)

Os aspectos apresentados dizem respeito à terceirização como um todo no Brasil, para as empresas privadas e para a Administração Pública. No entanto, com o advento da nova lei, a utilização de empresa interposta se tornou legalizada.

$\mathrm{Na}$ Administração Pública Direta e Indireta a terceirização "como contrato de fornecimento de mão de obra, [...] não tem guarida [...], porque a Constituição [da República de 1988], no art. $37^{3}$, inciso II, exige que a investidura em cargos, empregos ou funções se dê sempre por concurso público" (DI PIETRO, 2012, p. 223).

A Lei no 13.429 , de 31 de março de 2017, que redefiniu o que seja trabalho temporário, como explicitado neste trabalho, ainda continua sendo uma exceção. Constitucionalmente falando, a regra é prover com recursos humanos a Administração Pública, por meio de concursos públicos e não por meio de contratos de prestação de serviços terceirizados.

Tais contratos têm sido celebrados sob a fórmula de prestação de serviços técnicos especializados, de tal modo a assegurar uma aparência de legalidade. No entanto, não há, de fato, essa prestação de serviços por parte da empresa contratada, já que esta se limita, na realidade, a fornecer mão de obra para o Estado; ou seja, ela contrata pessoas sem concurso público, para que prestem serviços em órgãos da Administração direta e indireta do Estado. (DI PIETRO, 2012, p. 223).

\footnotetext{
${ }^{3}$ Art. 37. A administração pública direta e indireta de qualquer dos Poderes da União, dos Estados, do Distrito Federal e dos Municípios obedecerá aos princípios de legalidade, impessoalidade, moralidade, publicidade e eficiência e, também, ao seguinte:

[...]

II - a investidura em cargo ou emprego público depende de aprovação prévia em concurso público de provas ou de provas e títulos, de acordo com a natureza e a complexidade do cargo ou emprego, na forma prevista em lei, ressalvadas as nomeações para cargo em comissão declarado em lei de livre nomeação e exoneração; (Redação dada pela Emenda Constitucional no 19, de 1998) (BRASIL, 1988).
} 
Ressalte-se que a prestação de serviços anteriormente vetada à Administração Pública era a mesma para a inciativa privada, ou seja, o "aluguel de pessoas" por empresas que comercializam a força de trabalho dessas pessoas. Isso era considerada uma terceirização "atípica", pois a terceirização "clássica" (ou "externa"), tem por objeto um determinado serviço ou produto e nunca o trabalhador (PAIXÃO; LOURENÇO FILHO, 2014, p. 63).

Mesmo para a contratação de serviços por intermédio de empresa interposta nos setores de conservação, limpeza, vigilância, que já eram permitidos antes da nova lei, o trabalhador perdia a dignidade, pois deixava de ser o empregado da empresa tomadora, aquela que realmente estava mais próxima de si, para ser de outra empresa distante, mas que fato é a que assina sua carteira de trabalho.

O que se percebe, então, é a inclusão do trabalhador como mercadoria na cadeia produtiva da sociedade do trabalho. O lucro da empresa "prestadora de serviços" não estará na fabricação de um bem, no fornecimento de um serviço especializado ou na elaboração de trabalho intelectual qualificado. A empresa lucrará com a força de trabalho "alugada" a um tomador, o que implica concluir: o homem perde a perspectiva da centralidade do trabalho. Ao invés de figurar como protagonista da relação de trabalho, ocupando um dos seus polos, o homem passa a ser objeto de uma negociação de natureza comercial (PAIXÃO; LOURENÇO FILHO, 2014, p. 64).

Baseado no descrito anteriormente, prospecta-se a celeuma que a nova legislação tem potencial de causar no cenário jurídico brasileiro, haja vista, três Ações Diretas de Inconstitucionalidade protocoladas no STF logo em seguida à sanção da nova lei brasileira sobre terceirização.

No que tange a terceirização de serviços arquivísticos. A área possui regulamento próprio. Este regulamento é a Resolução no 6, do CONARQ, de 15 de maio de 1997, que dispõe sobre diretrizes quanto à terceirização de serviços arquivísticos públicos. Essa Resolução foi proposta e aprovada na 8 ${ }^{\underline{a}}$ Reunião Plenária Ordinária do CONARQ, de 12 de maio de 1997.

Vieira (2012), ao fazer considerações sobre a possibilidade de terceirização de um tipo de serviço arquivístico e analisando a ata da 56ª Reunião Plenária Ordinária do CONARQ, deduz que a definição dos serviços arquivísticos que podem ser terceirizados está ainda pendente de definição, contudo conclui, por exemplo, que a guarda de documentos não poderá ser terceirizada [grifo dos autores] "por se tratar de atividade essencial à gestão de documentos".

Oliveira (2015) realizou pesquisa utilizando-se de questionário para identificar motivos e frequência com que cada órgão, principalmente os integrantes do Sistema de Gestão de Documentos de Arquivo - SIGA, da Administração Pública Federal, optara por contratar serviços de arquivo terceirizados. A autora afirma que foram oferecidas diversas justificativas, inclusive falta de pessoal próprio para execução das tarefas arquivísticas. 
Oliveira (2015, p. 200), quanto à Resolução no 6, de 15 de maio de 1997, do CONARQ, afirma que esta foi aprovada visando parar a enorme frequência de contratação de serviços terceirizados. Assim, é possível inferir que, quando da sua aprovação, a terceirização de serviços arquivísticos, nesse tempo, era uma realidade patente.

Para Fogerty (1997, p. 55), contudo, em artigo do mesmo ano da Resolução nํㅡ, de 15 de maio de 1997, do CONARQ, a terceirização dos arquivos empresariais, por qualquer pretexto empresarial, já era uma opção velha, que sempre esteve na pauta das empresas e que continuaria a estar.

Pelo visto, 20 anos depois, Fogerty estava certo. Não que se concorde que seja o melhor caminho a terceirização de todos os serviços arquivísticos, o que não está em discussão neste trabalho, mas é preciso estar atento ao que se terceiriza e como esta atividade ocorre.

Balbino e Silva (2016, p. 111), que escreveram artigo sobre serviços terceirizados de gestão de documentos, e também analisaram a Resolução ํㅡ 6, de 15 de maio de 1997, do CONARQ, concluem que:

embora a terceirização possa ser aplicável em atividades de apoio relacionadas a arquivos, devido à legislação vigente, não é aconselhável fazê-lo, já que, [...] a principal finalidade da terceirização pode estar associada apenas a diminuição de custo. (BALBINO; SILVA, 2016, p. 111, grifo nosso).

Discorda-se dos autores, pois reduzir custos é também um aspecto de eficiência do Poder Público. Contudo, reduzir custos não pode vir atrelado à precarização dos serviços públicos e à perda de direitos trabalhistas dos prestadores de serviço.

Depreende-se da leitura dos artigos anteriores (VIEIRA, 2012; OLIVEIRA, 2015; BALBINO; SILVA, 2016) que a Resolução n ㅜ 6e 15 de maio de 1997, do CONARQ, entrou em vigor depois que a terceirização de serviços arquivísticos estava consolidada no Brasil. A Resolução veta parcialmente a terceirização. Parcialmente, pois permite a terceirização de "atividades técnicas auxiliares". Contudo, não esclarece o que são estas atividades.

Após verificação de atas de 84 reuniões do CONARQ, identificou-se que em 21 delas (25\%) o tema da terceirização de serviços arquivísticos foi pauta de reunião ou, mesmo não estando na pauta do dia, foi mencionado ou discutido. Diante disso, percebeu-se que era preciso rever o texto da Resolução no 6, de 15 de maio de 1997, do CONARQ, portanto, na 49ª Reunião Plenária Ordinária, de 10 de dezembro de 2008, fora apresentada a questão da reformulação da Resolução. Contudo, depois de 35 reuniões, até março de 2016, não foi apresentada, ainda, uma proposta concreta quanto à reformulação em questão. 


\section{Serviços arquivísticos terceirizados na Petrobras}

A realização da pesquisa pretendeu conhecer um problema da vida prática, ou seja, como se encontram empiricamente os recursos humanos de serviços arquivísticos terceirizados na Petrobras, empresa de energia, com foco em produção de óleo e gás, sediada no Rio de Janeiro, com atuação em todo o território nacional, bem como em outros países. A pesquisa foi aplicada em uma gerência de serviços de informação e documentação, que possuía outras cinco gerências setoriais hierarquicamente inferiores, sendo uma de biblioteca e quatro de serviços arquivísticos, que atendem a diversas áreas da companhia, tanto técnicas quanto administrativas.

Os resultados seguintes sobre serviços arquivísticos terceirizados são parte de uma pesquisa maior que diagnosticou um tipo de serviço arquivístico na Petrobras. Os serviços terceirizados específicos foram os de guarda externa de documentos, sobre os quais não se abordará neste trabalho, que pretende focar nos recursos humanos terceirizados, e nos serviços executados de forma genérica.

Para a realização desta pesquisa utilizou-se do seguinte método:

- Pesquisa da legislação e normas que regem as estatais brasileiras e sua gestão de documentos;

- Autorização para utilização de dados, informações e documentos da gerência de informação e documentação da Petrobras;

- Solicitação por meio do Serviço de Informação ao Cidadão de cópia de contratos de serviços arquivísticos terceirizados para acesso a seus dados;

- Confecção de planilha contendo os contratos de serviços de informação e documentação celebrados de 2006 a 2016 pela Petrobras, categorizando-os por tipo de serviço e por empresa terceirizada;

- Elaboração de instrumento de coleta de dados sobre recursos humanos em forma de planilha para preenchimento com: nome do empregado, escolaridade, formação profissional e tempo de experiência ou de serviço com gestão de documentos;

- Envio do instrumento de coleta elaborado a quatro gerentes setoriais de documentação técnica e legal da Petrobras para preenchimento;

- Identificação de empregados próprios e terceirizados atuantes com gestão de documentos.

Aplicado o instrumento de coleta de dados, procedeu-se a sua análise. Após consolidação das planilhas recebidas dos quatro gerentes, constatou-se que havia na gerência maior, que abarcava estas quatro setoriais, 40 empregados próprios (concursados) e 137 prestadores de serviços de nove contratos diversos. 
A escolaridade das equipes, tanto de empregados próprios quanto dos prestadores de serviço, em sua maioria, é de nível superior. Contudo, enquanto apenas 3,6\% dos prestadores de serviços possuem pós-graduação, o percentual dos empregados próprios é de $35 \%$, percentual 10 vezes maior.

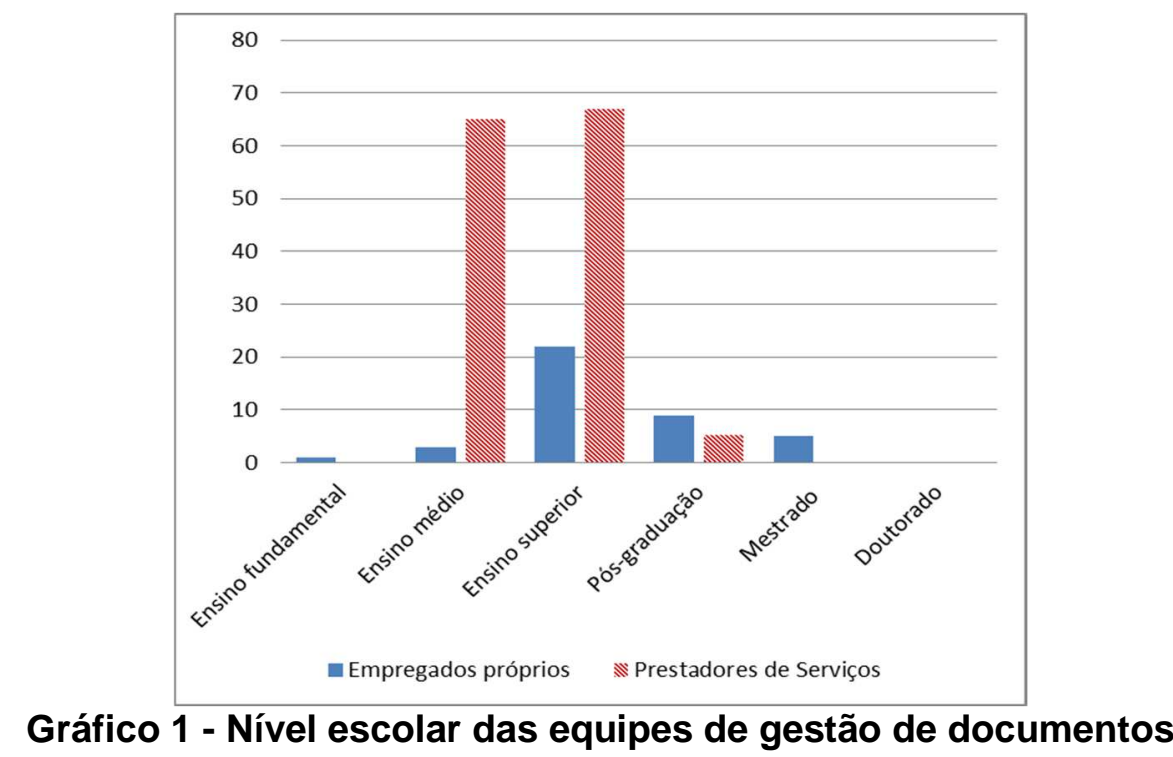

Fonte: Os autores (2017).

Isso talvez se explique, no caso da Administração Pública, por que as empresas visam o "melhor preço" para se ganhar um processo licitatório, que geralmente é aquela paga menos a seus trabalhadores. Assim, não haverá também investimento em educação continuada:

Com isso, vem à tona uma das maiores desvantagens da situação de trabalhador terceirizado. Não há investimento em formação, qualificação e aperfeiçoamento profissional. Como a prestadora de serviços tem como única fonte de lucro a força de trabalho humano (ou seja, o salário do trabalhador), qualquer tipo de treinamento importará em custo para a empresa (que não dispõe de nenhuma outra fonte de recursos). O resultado será um trabalhador desqualificado, sem formação, sem perspectiva, sem futuro (PAIXÃO; LOURENÇO FILHO, 2014, p. 65).

Ao analisar a formação superior das equipes, tanto dos empregados próprios quanto dos prestadores de serviços, verifica-se outra diferença entre elas. Enquanto entre os empregados próprios há somente uma empregada que é arquivista e bibliotecária, ou seja, $2,7 \%$ da equipe com formação específica em Arquivologia, o percentual dos prestadores de serviços é de $41,7 \%$. A equipe própria que trabalha com gestão de documentos é formada por 70,3\% de bibliotecários. A diferença pode ser verificada no Gráfico 2.

Este fato ocorre por que no plano de carreiras da Petrobras não há previsão de cargo para arquivistas, logo não se faz concurso público para este tipo de profissional, assim os bibliotecários assumem as atividades de gestão de documentos. 
Foi imperioso saber o porquê a quantidade de "outras" formações de nível superior ser tão alta em contratos de serviços arquivísticos, por exemplo, igual a de bibliotecários. Que outras formações têm contribuído para a gestão de documentos? Há interdisciplinaridade na execução das atividades? Ao analisar-se a questão, foi verificado que, na verdade, os profissionais de outras formações de nível superior, inclusive alguns administradores, atuam, na verdade, como técnicos de arquivo. Estes trabalhadores não exercem suas profissões. Isso talvez ocorra por falta de oportunidade em suas áreas de origem. Outra possibilidade é a dos técnicos terem se formado em outras áreas após estarem trabalhando com gestão de documentos.

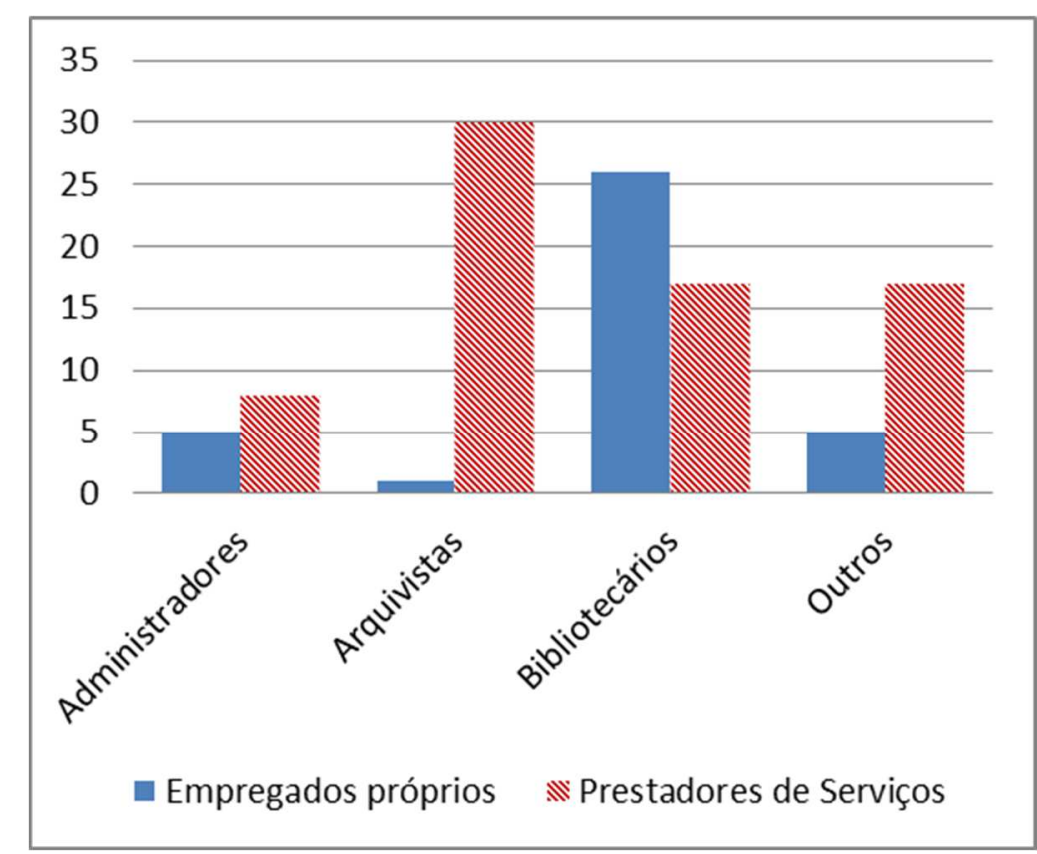

\section{Gráfico 2 - Formação superior da equipe}

Fonte: Os autores (2017).

A Petrobras contrata empresas prestadoras de serviços que aloca recursos humanos terceirizados para o desenvolvimento das atividades de gestão de documentos. Não ocorre a contratação de técnicos, especialistas ou consultores. No período de 2006 a 2016, por exemplo, não houve esse tipo de contratação na gerência de informação e documentação da empresa.

Dessa forma, a empresa estatal conta com a experiência de seus próprios empregados, que em relação aos prestadores de serviço, realmente possuem maior experiência em gestão de documentos, como apresentado no Gráfico 3:

Enquanto a grande maioria dos prestadores de serviço $(60,3 \%)$ possui até cinco anos de experiência, a maioria dos empregados próprios (75\%) possui mais de 10 anos de experiência. 
Em levantamento realizado em relatórios e sistemas da Petrobras, identificou-se, no período de 2006 a 2016, 37 contratos celebrados de serviços de informação e documentação com 13 empresas diferentes. Foi calculada uma média de 3,6 contratos por empresa e uma média de 4,3 contratos celebrados por ano.

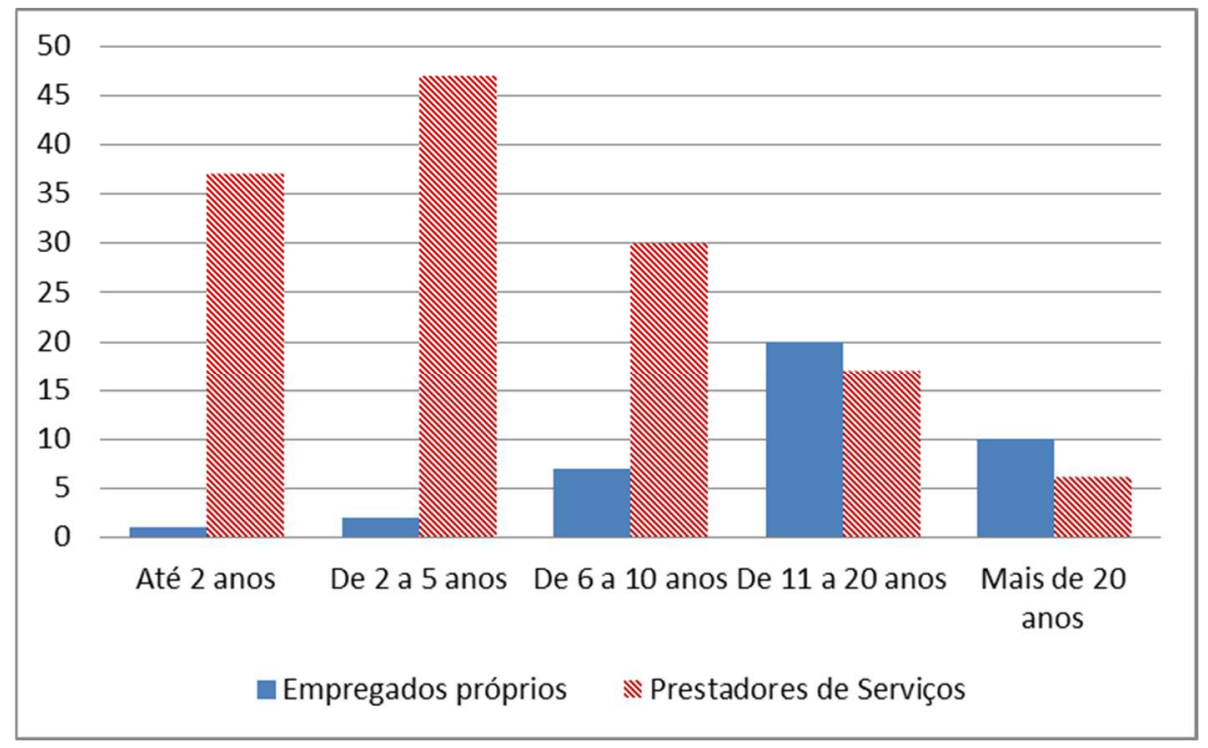

\section{Gráfico 3 - Experiência da equipe em gestão de documentos}

Fonte: Os autores (2017).

No final de 2016, 15 contratos de serviços de informação e documentação estavam em vigor na Petrobras, segundo levantamento realizado.

No Gráfico 4, apresenta-se o percentual de distribuição desses contratos pelas empresas contratadas, no período de 2006 a 2016. No período, 64\% dos contratos ficaram concentrados em três fornecedores. Verifica-se, contudo que houve, no período pesquisado, uma diversidade de empresas fornecedoras de serviços terceirizados.

Em 2017, as três empresas fornecedoras não mais prestam serviços à Petrobras, pois a uma saiu do mercado, outra foi comprada por sua maior concorrente e a terceira não apresentou proposta de preços nas últimas licitações realizadas. 


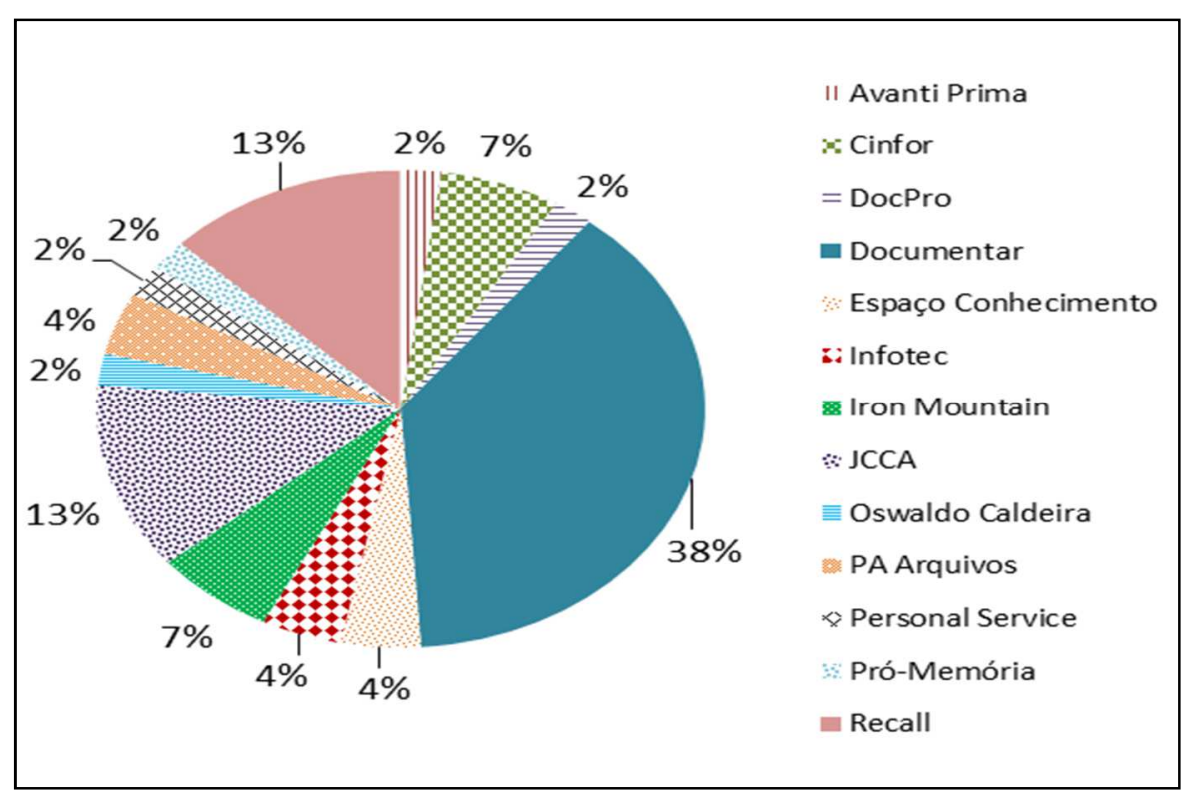

Gráfico 4 - Percentual de contratos por empresas

Fonte: Os autores (2017).

Os contratos na Petrobras, geralmente, possuem prazo de duração de dois anos. Isso para a empresa tomadora de serviços, estrategicamente e economicamente é, por vezes, bem interessante, pois se uma prestadora de serviços for ruim, em nova contratação há a possibilidade de troca de fornecedor, ou mesmo não haver fornecedor, caso haja alguma crise, ou falta de recursos, ou seja necessário economizar por quaisquer motivos. Contudo sofre o trabalhador terceirizado, pois nada garante a renovação de seu contrato:

O trabalhador terceirizado vê o futuro como algo aterrorizante. É quase certa a perda do emprego com o final do contrato. Afinal de contas, sua permanência na "prestadora" está condicionada à existência de uma "tomadora". A "tomadora" tem liberdade para contratar a empresa que oferecer o melhor "pacote". O futuro equivale, para o trabalhador terceirizado, ao vazio, à ausência, ao incerto (PAIXÃO; LOURENÇO FILHO, 2014, p. 66).

Ao categorizarem-se os contratos da Petrobras por tipo de serviços de informação e documentação, tem-se apresentado na Tabela 1, serviços de biblioteca, de diagnóstico, de organização de documentos, de gestão de arquivo e de guarda externa de documentos.

Verificou-se que $75,7 \%$ dos contratos do período contemplado na pesquisa realizada foram de serviços arquivísticos, quando comparada com os contratos de biblioteca, haja vista, que os empregados próprios são bibliotecários. 
Tabela 1 - Contratos por tipo de serviços: 2006 a 2016

\begin{tabular}{|l|r|c|}
\hline Serviços terceirizados & $\begin{array}{c}\text { Contratos } \\
\text { 2006-2016 }\end{array}$ & $\%$ \\
\hline Biblioteca & 9 & 24,3 \\
\hline Diagnóstico & 2 & 5,4 \\
\hline Organização & 10 & 27,0 \\
\hline Gestão & 7 & 18,9 \\
\hline Guarda Externa & 9 & 24,3 \\
\hline Total & $\mathbf{3 7}$ & $\mathbf{1 0 0}$ \\
\hline
\end{tabular}

Fonte: Os autores (2017).

Ao se retirar os serviços de biblioteca para análise somente dos serviços arquivísticos, obtém-se os percentuais de contratos celebrados, no período de 2006 a 2016, para diagnóstico, organização de documentos, gestão de arquivo e guarda externa de documentos apresentados na Tabela 2.

Percebe-se que, os serviços de organização de documentos representam mais de um terço dos contratos de serviços arquivísticos celebrados no período de 2006 a 2016.

Os serviços contratados são utilizados em situações de rotina e, eventualmente, há contratação para situações extraordinárias.

Tabela 2 - Contratos por tipo de serviços arquivísticos: 2006 a 2016

\begin{tabular}{|l|r|c|}
\hline Serviços arquivísticos & $\begin{array}{c}\text { Contratos } \\
\text { 2006-2016 }\end{array}$ & $\%$ \\
\hline Diagnóstico & 2 & 7,1 \\
\hline Organização & 10 & 35,7 \\
\hline Gestão & 7 & 25,0 \\
\hline Guarda Externa & 9 & 32,1 \\
\hline Total & $\mathbf{2 8}$ & $\mathbf{1 0 0}$ \\
\hline
\end{tabular}

Fonte: Os autores (2017).

Após verificação dos contratos a que se teve acesso, se identificou os serviços arquivísticos terceirizados utilizados pela Petrobras. São eles a organização de arquivos, a digitalização, conservação/preservação, guarda externa de documentos (equivalente a armazenamento), movimentação e eliminação de documentos.

Não foi identificada, após a aplicação do instrumento de coleta de dados e análise dos contratos, no período de 2006 a 2016, a contratação de serviços arquivísticos de consultoria, elaboração de instrumentos arquivísticos, classificação, avaliação, aquisição, descrição, higienização, restauração.

Verificou-se que a metodologia utilizada nas tarefas executadas por terceiros é definida, na maioria das vezes, pelas unidades responsáveis pela gestão de documentos e não pelas empresas contratadas. 


\section{Considerações finais}

Em 31 de março de 2017, foi sancionada a Lei oㅜ 13.429, que mudou completamente o cenário jurídico, sem que fosse possível verificar, nesta pesquisa, seus efeitos no Direito Trabalhista, bem como no desempenho das empresas ou nos serviços arquivísticos terceirizados.

É preciso monitorar a terceirização de serviços arquivísticos após o advento da Lei, visando verificar que modificações podem ocorrer no mercado para os arquivistas, além da degradação dos direitos trabalhistas, que impactos podem ocorrer na educação continuada do trabalhador e consequentemente na evolução da Arquivologia brasileira.

É preciso investigar com o tempo se após o advento desta lei haverá diminuição, por exemplo, de concursos públicos para o cargo de arquivistas.

É possível afirmar que a questão da terceirização de serviços arquivísticos no Brasil, embora formalmente regulamentada, nunca chegou a ser atendida, de fato, uma vez que traz em seu bojo dispositivos conflitantes e que não atendem à realidade das instituições e órgãos públicos quanto ao tratamento arquivístico necessário.

É preciso que sejam definidas o que são atividades arquivísticas técnicas auxiliares para que se possa entender se serão caracterizadas como terceirização "atípica", o "aluguel de pessoas", ou como terceirização "clássica" (ou "externa"), como, por exemplo, prestação de serviços de digitalização, higienização, guarda externa de documentos, que podem ser realizados fora das instalações da empresa tomadora. Acredita-se que se for utilizado esta conceituação na hora de sua definição, isso auxiliará bastante aos profissionais da informação.

Foi verificado que, de um total de 40 empregados próprios (concursados) de uma área de serviços arquivísticos da Petrobras com 137 prestadores de serviços de nove contratos diversos, constatou-se que, proporcionalmente o nível escolar dos empregados próprios é maior que o nível dos prestadores de serviço. Com a ampliação do escopo da terceirização após o advento da Lei ํㅜ 13.429, de 31 de março de 2017, é possível que esta diferença se amplie, não somente onde foi aplicada a pesquisa, mas em outras instituições e órgãos públicos.

Tanto na equipe própria, quanto na equipe contratada, outros profissionais de nível superior, que não arquivistas e bibliotecários, estão trabalhando fora de suas áreas de origem, geralmente, atuando como técnicos de arquivo.

Empregados próprios também possuem mais anos de experiência em atuação na gestão de documentos que os prestadores de serviço.

Dessa forma, o que antes era uma suspeita, neste trabalho se comprova, há grande diferença entre empregados próprios e terceirizados quanto à qualificação técnica, formação e experiência. 
Espera-se que esta pesquisa contribua para uma ampliação do tema que requer discussões no que tange tanto a esfera da educação quanto a do trabalho no âmbito da teoria e prática arquivísticas.

\section{REFERÊNCIAS}

ALVES, G. A. P. Terceirização e capitalismo no Brasil: um par perfeito. Revista do Tribunal Superior do Trabalho, Brasília, DF, v. 80, n. 3, p. 90-105, jul./set. 2014.

ARIENTI, W. L. Uma análise regulacionista das reformas do estado capitalista: rumo ao estado pós-fordista?. Textos de Economia, Florianópolis, v. 8, n. 1, p. 1-36, 2002. Disponível em: https://periodicos.ufsc.br/index.php/economia/article/view/6059/5628. Acesso em: 08 set. 2017. BALBINO, G. M. S.; SILVA, W. A. Outsourcing em arquivos públicos: uma análise crítica sobre a gestão documental terceirizada. Ágora, Florianópolis, v. 26, n. 52, p. 91-118, jan./jun. 2016. Disponível em: https://agora.emnuvens.com.br/ra/article/view/599. Acesso em: 24 ago. 2017.

BOWLES, S.; BOYER, R. Wages, aggregate demand, and employment in an open economy: an empirical investigation. In: EPSTEIN, G. A.; GINTIS, H. M. (ed.). Macroeconomic policy after the conservative era: studies in investment, saving, and finance. New York: Cambridge University Press, 1995. p. 143-160.

BRASIL. Constituição (1988). Constituição da República Federativa do Brasil. Brasília, DF, 05 out. 1988. Disponível em: http://www.planalto.gov.br/ccivil_03/constituicao/constituicao.htm. Acesso em: 05 maio 2014.

BRASIL. Lei no 13.429, de 31 de março de 2017. Altera dispositivos da Lei no 6.019, de 3 de janeiro de 1974, que dispõe sobre o trabalho temporário nas empresas urbanas e dá outras providências; e dispõe sobre as relações de trabalho na empresa de prestação de serviços a terceiros. Diário Oficial [da] República Federativa do Brasil, Poder Executivo, Brasília, DF, 31 mar. 2017. Edição extra. Disponível em: http://www.planalto.gov.br/ccivil_03/_ato20152018/2017/lei/L13429.htm. Acesso em: 05 maio 2017.

BRASIL. Lei no 8.159, de 08 de janeiro de 1991. Dispõe sobre a política nacional de arquivos públicos e privados e dá outras providências. Diário Oficial [da] República Federativa do Brasil, Poder Executivo, Brasília, DF, 09 jan. 1991. Disponível em: http://www.planalto.gov.br/ccivil_03/leis/L8159.htm. Acesso em: 29 mar. 2015.

BRASIL. Tribunal Superior Eleitoral. Secretaria de Gestão da Informação. Acervo arquivístico: diagnóstico 2008. Brasília, DF: TSE, 2009. (Publicações arquivísticas do TSE, 1). Disponível em: http://www.tse.jus.br/hotsites/catalogopublicacoes/pdf/acervo_arquivistico/Diagnostico_do_acervo_arquivistico.pdf. Aceso em: 3 jan. 2017. 
CARVALHO, A. C. L.; CORRÊA, L. B. Terceirização no âmbito da empresa privada. Revista do Tribunal Superior do Trabalho, Brasília, DF, v. 80, n. 3, p. 36-57, jul./set. 2014.

CONSELHO NACIONAL DE ARQUIVOS (Brasil). Resolução nº 6, de 15 de maio de 1997. Dispõe sobre diretrizes quanto à terceirização de serviços arquivísticos públicos. Diário Oficial [da] República Federativa do Brasil, Poder Executivo, Brasília, DF, 23 maio 1997. Seção 1, p.

Disponível

em:

http://pesquisa.in.gov.br/imprensa/jsp/visualiza/index.jsp?data=23/05/1997\&jornal=1\&pagina=6 \&totalArquivos=104. Acesso em: 20 jan. 2016.

DI PIETRO, M. S. Z. Parcerias na administração pública: concessão, permissão, franquia, terceirização, parceria público-privada e outras formas. 9. ed. São Paulo: Atlas, 2012.

EASTWOOD, T. What is archival theory and why is it important? Archivaria, Ottawa, v. 37, p. 122-130, Spring. $1994 . \quad$ Disponível em: http://archivaria.ca/index.php/archivaria/article/view/11991/12954. Acesso em: 17 jun. 2017. FOGERTY, J. Archival brinkmanship: downsizing, outsourcing, and the records of corporate America. The American Archivist, Menasha, v. 60, n. 1, p. 44-55, Winter 1997.

FÜHRER, M. C. A.; FÜHRER, M. R. E. Resumo de Direito do Trabalho. 17. ed. São Paulo: Malheiros, 2005.

OLIVEIRA, M. I. A terceirização das atividades arquivísticas na Administração Pública Federal. Acervo, Rio de Janeiro, v. 28, n. 2, p. 192-205, jul./dez. 2015.

PAIXÃO, C.; LOURENÇO FILHO, R. Impactos da terceirização no mundo do trabalho: tempo, espaço e subjetividade. Revista do Tribunal Superior do Trabalho, Brasília, DF, v. 80, n. 3, p. 58-74, jul./set. 2014.

PORTO, L. V. Terceirização: fundamentos filosóficos, sociológicos, políticos, econômicos e jurídicos da jurisprudência do TST (Súmula no 331). Revista do Tribunal Superior do Trabalho, Brasília, DF, v. 80, n. 3, p. 150-170, jul./set. 2014.

TEIXEIRA, M.; PELATIERI, P. Terceirização e precarização do mercado de trabalho brasileiro. In: DAU, D. M.; RODRIGUES, I. J.; CONCEIÇÃO, J. J. (org.). Terceirização no Brasil: do discurso da inovação à precarização do trabalho: atualização do debate e perspectivas. São Paulo: Annablume: CUT, 2009. p. 19-28.

VIEIRA, R. L. Considerações sobre a possibilidade de terceirização no serviço de guarda de documentos públicos. Conteúdo Jurídico, Brasília, DF, 10 dez. 2012. Disponível em: http://www.conteudojuridico.com.br/?artigos\&ver=2.41063\&seo=1. Acesso em: 01 jul. 2017. 